\title{
CARACTERIZAÇÃO MORFOLÓGICA DO RAMO, SEMENTES E PLÂNTULAS DE Matayba guianensis Aubl. E PRODUÇÃO DE MUDAS EM DIFERENTES RECIPIENTES E SUBSTRATOS ${ }^{1}$
}

\author{
Francielli Bao², Liana Baptista de Lima ${ }^{3}$ e Petterson Baptista da Luz ${ }^{4}$
}

\begin{abstract}
RESUMO - Matayba guianensis Aubl. é uma Sapindaceae de porte arbustivo ou arbóreo de grande ocorrência no Cerrado brasileiro, com papel fundamental no fornecimento de recursos para formigas e abelhas. Apresenta rápido crescimento e é importante para recuperação de áreas degradadas, mas pouco se conhece sobre a sua produção de mudas. Diante disso, o objetivo deste estudo foi descrever a morfologia do ramo e da germinação de sementes e plântulas de Matayba guianensis Aubl. em seu desenvolvimento pós-seminal, bem como definir o tipo de substrato e recipiente adequados para emergência de plântulas e produção de mudas desta espécie. Foram avaliados três tipos de recipientes: saco de polietileno preto; tubete e bandeja de isopor, com cinco tipos de substratos: areia; terra; terra-areia-esterco (1:1:1); substrato comercial e fibra de coco, com quatro repetições de 25 sementes em cada tratamento. O ramo, fruto, semente, plântulas e seus eventos morfológicos foram descritos. O ramo é cilíndrico, com folhas paripinadas e alternas; fruto seco, deiscente e sementes com grande quantidade de arilo; a germinação é criptocotiledonar e hipógea. Sua maior porcentagem de emergência ocorreu no recipiente isopor com $91 \%$ das sementes germinadas em substrato comercial, seguida de fibra de coco (88\%). O desenvolvimento da raiz e do caule foi maior em tubete e em saco plástico, utilizando-se substrato comercial ou fibra de coco.
\end{abstract}

Palavras chave: Germinação; Testes de emergência; Desenvolvimento pós-seminal.

\section{MORPHOLOGICAL CHARACTERIZATION OF BRANCH, SEEDS AND SEEDLINGS OF Matayba guianensis Aubl. AND SEEDLING PRODUCTION IN DIFFERENT CONTAINERS AND SUBSTRATES}

\begin{abstract}
Matayba guianensis Aubl . is a shrubby or arborial Sapindaceae quite common in the Brazilian Cerrado with a key role in providing resources for ants and bees. It presents a rapid growth, and is important for the recovery of degraded areas, but little is known about its seedlings production. Therefore, the aim of this study was to describe the morphology of the branch and the seed germination and of seedling Matayba guianensis Aubl . in its post-seminal development and define the type of substrate and container suitable for seedling emergence and seedling production of this species. We evaluated three types of containers: black polyethylene bags, cartridge and polystyrene tray, with 5 kinds of substrates: sand, earth, earth - sand - manure (1:1:1); commercial substrate, and coconut fiber, with 4 replicates of 25 seeds per treatment. The branch, fruit, seed, seedling and their morphological events were described. The branch is cylindrical with paripinnate and alternate leaves, the fruit is dry and dehiscent. The seeds have a large amount of aryl, and the germination is cryptocotylar and hypogeal. The highest percentage of emergence occurred in styrofoam container with $91 \%$ of the seeds germinated in commercial substrate, followed by coconut fiber (88\%). The development of root and stem were higher in tubes and plastic bags, using coconut fiber or commercial substrate.
\end{abstract}

Keywords: Germination; Emergence test; Post-seminal development.

\footnotetext{
${ }^{1}$ Recebido em 15.04.2012 aceito para publicação em 03.12.2013

${ }^{2}$ Programa de Pós-Graduação em Biologia Vegetal, Universidade Estadual Paulista "Julio de Mesquita Filho", Instituto de Biociências, UNESP, Rio Claro, Brasil.E-mail: <franbao@yahoo.com.br>.

${ }^{3}$ Universidade Federal de Mato Grosso do Sul, Centro de Ciências Biológicas e da Saúde, UFMS, Brasil. E-mail: <lianablima@gmail.com>.

${ }^{4}$ Departamento de Agronomia da Universidade do Estado de Mato Grosso, Campus Universitário de Cáceres, UNEMAT, Brasil. E-mail: <petterbaptista@yahoo.com.br>.
} 


\section{INTRODUÇÃO}

A família Sapindaceae está inclusa na ordem Sapindales (APG III, 2009), com ocorrência no Brasil de 25 gêneros e 411 espécies (SOUZA; LORENZI, 2005). O gênero Matayba Aubl. está distribuído desde o México até o Norte da Argentina (FERRUCCI, 1991), apresentando 31 espécies, sendo 17 endêmicas; no Brasil, está presente em diversas formações vegetacionais (SOMNER et al. , 2010).

No Cerrado brasileiro, é encontrada a Matayba guianensis Aublet 1775, conhecida por Cambotã, de porte arbustivo ou arbóreo (SOUZA; LORENZI, 2005). A espécie desempenha importante papel ecológico como fornecedora de alimento para formigas, pela grande quantidade de arilo nas sementes, além da grande visitação de abelhas às suas flores (CARVALHO; OLIVEIRA, 2010). Possui dispersão zoocórica, é monoica e sua frutificação geralmente ocorre em épocas chuvosas (RESSEL et al., 2002).

Uma das grandes dificuldades encontradas por quem trabalha com espécies arbóreas nativas é o lento crescimento, tornando-se importante o estudo de estratégias que visem à produção de mudas de qualidade, com rápida germinação e desenvolvimento das plântulas (CUNHA et al., 2005). Nessas espécies arbóreas, também é encontrada grande variação na germinação, no crescimento e na morfologia de suas plântulas, dificultando a identificação das espécies (GOMES et al., 1991). O estudo da germinação e o conhecimento morfológico permitem caracterizar as espécies e diferenciálas, auxiliando em trabalhos de inventários e de manejo florestal (PAOLI; BIANCONI, 2008).

A fase inicial e a influência da morfologia funcional das plântulas no processo de estabelecimento são importantes para o entendimento das espécies dentro dos biomas (RESSEL et al., 2002), além de fornecer informações do ponto de vista taxonômico, através do conhecimento das estruturas das plântulas (PAOLI; SANTOS, 1998). As avaliações da germinação contribuem para a adequação de métodos para produção de mudas (FERREIRA etal., 1998)dealta qualidade erápida germinação.

A germinação rápida e o desenvolvimento homogêneo promovem um povoamento mais uniforme no campo, onde as plantas estarão expostas às condições adversas do ambiente e do solo, tornando-se determinantes para o desenvolvimento vegetal (PACHECO et al., 2006; GUREVITCH et al., 2009).

Revista Árvore, Viçosa-MG, v.38, n.1, p.63-71, 2014
Fatores como aeração e capacidade de retenção de água do substrato podem variar de acordo com o recipiente utilizado e tem grande efeito sobre a germinação e emergência de plântulas. De acordo com Popinigs (1985), é importante o estudo de diferentes substratos para que se obtenha maior eficiência na produção de mudas. O tipo de substrato afeta a germinação, a emergência de plântulas e o desenvolvimento das mudas, por fornecer a água, os nutrientes e garantir adequada aeração (CARNEIRO, 1995). Entretanto, com relação a espécies nativas, pouco se conhece sobre a necessidade de cada espécie, e quais são as características que o substrato deve apresentar para a produção de mudas de alta qualidade. Da mesma maneira, a escolha do recipiente mais adequado está sujeita a diversos fatores, como seu tamanho e formato (BRASIL, 2009), sendo dependentes das condições do local e da espécie que será utilizada (AGUIAR; MELLO, 1974).

Diante disso, o objetivo deste estudo foi descrever a morfologia do ramo e da germinação de sementes e plântulas de Matayba guianensis Aubl. em seu desenvolvimento pós-seminal, bem como definir o tipo de substrato e o recipiente adequados para a emergência de plântulas e a produção de mudas dessa espécie.

\section{MATERIAL E MÉTODOS}

As sementes foram coletadas na Reserva Particular de Patrimônio Natural ( $20^{\circ} 27^{\prime} \mathrm{S}$, 54 $4^{\circ} 37^{\circ} \mathrm{W}$ ) da Universidade Federal do Mato Grosso do Sul (UFMS), localizada no Município de Campo Grande. Essa reserva possui área de 40 ha e Cerradão como vegetação predominante. Seu clima é tropical subúmido, com temperatura média anual de $26^{\circ} \mathrm{C}$ (ALLEM; VALLS, 1987).

Os frutos, do tipo cápsula, foram coletados de 12 indivíduos, distantes aproximadamente $5 \mathrm{~m}$ um do outro. As sementes foram extraídas manualmente e lavadas com água corrente para a remoção do arilo e secas sobre bancada de laboratório a $25^{\circ} \mathrm{C}$ por $48 \mathrm{~h}$. O experimento foi conduzido no viveiro experimental (com sombrite de 50\%) instalado na Universidade Federal do Mato Grosso do Sul. De cada intervalo do processo germinativo foram retiradas plântulas, armazenadas em álcool 70\% para posteriormente serem feitas ilustrações dos eventos morfológicos externos (SILVA et al., 2012). A descrição morfológica do ramo, do fruto, da semente e de seus estágios iniciais foi baseada nas obras de Font-Quer (1963), Vidal e Vidal (1995), Joly (1993), Gonçalves e Lorenzi (2007) e Judd et al. (2009). 
Foram avaliados três tipos de recipientes: saco de polietileno preto $(15 \times 25 \mathrm{~cm})$, tubete $(2,60 \mathrm{~cm}$ de diâmetro x $13 \mathrm{~cm}$ de altura) e bandeja de isopor (128 células nas dimensões de 680 mm x 340 mm x 60 mm de profundidade), com cinco tipos de substratos: areia, terra comum (latossolo vermelho), terra-areia-esterco (esterco de gado) (1:1:1), substrato comercial (plantmax) e fibra de coco. O delineamento estatístico foi em esquema fatorial 3 x 5 (três recipientes e cinco substratos) com quatro repetições de 25 sementes em cada tratamento. As sementes foram depositadas sob o nível dos substratos, com irrigação duas vezes ao dia. A emergência de plântulas foi acompanhada diariamente até a estabilização, que ocorreu com 28 dias, sendo consideradas na contagem aquelas que apresentavam qualquer parte sobressaída acima da superfície. Ao final do período experimental, que compreendeu a estabilização da germinação até a fase das plântulas, foram removidas aleatoriamente dos recipientes 20 plântulas de cada tratamento, totalizando 300 plântulas, para determinação do número de folhas, do comprimento da raiz e do caule e da espessura do coleto. A seguir, as folhas, caules e raízes das plântulas foram retiradas e dessecadas em estufa a $80{ }^{\circ} \mathrm{C}$ por $24 \mathrm{~h}$, para determinação da massa seca das respectivas frações (MESQUITA et al., 2009; SANTOS et al., 2009; DUARTE; NUNES, 2012).

Os dados foram submetidos à análise estatística a $1 \%$ de probabilidade de erro, através dos programas Statistica e Assistat 7.6 Beta (SILVA; AZEVEDO, 2009), para comparação das médias, através do teste de Tukey.

\section{RESULTADOS}

\subsection{Descrição morfológica do ramo, fruto e semente}

O ramo é cilíndrico, com folhas paripinadas e alternas; as nervuras dos folíolos são secundárias arqueadas; o ápice e a base são obtusos; e os folíolos são recurvados (Figura 1). O fruto é do tipo cápsula (Figura 1A), seco e, neste caso, deiscente (Figura 1B), oriundo de um ovário com dois carpelos, cada um com uma semente. A semente é preta e brilhante, apresenta arilo carnoso e branco-amarelado (Figura 1C). O endosperma é oleoaginoso, de coloração esbranquiçada. Apresenta de duas a três sementes por fruto, com média de $0,19 \mathrm{~g}$.

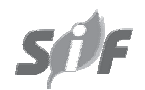

\subsection{Descrição morfológica da germinação e das plântulas}

A germinação das sementes é classificada como criptocotiledonar e hipógea, e a semente se mantém sob o nível do substrato durante o processo germinativo. A germinação começa com o rompimento do tegumento e a protrusão da raiz primária, que emerge juntamente com o hipocótilo (Figura 2A), seguida do desenvolvimento do epicótilo (Figura 2B), da raiz primária e do protófilo (Figura 2C), formando uma plântula completa com raiz primária, hipocótilo, epicótilo e par de folhas jovens (Figura 2D). As plântulas com 30 dias apresentaram média de três folhas, as raízes $9,00 \mathrm{~cm}$ de comprimento, o caule $5,70 \mathrm{~cm}$ e a espessura média do coleto $1,03 \mathrm{~cm}$.

\subsection{Efeito de recipientes e substratos sobre a emergência de plântulas}

A maior porcentagem de emergência foi obtida quando se utilizou substrato comercial ou fibra de coco em recipiente de isopor (Tukey, $\mathrm{P}<0,001$ ). Os substratos areia, terra e T-A-E em qualquer dos recipientes não foram adequados para a emergência de plântulas (Tabela 1).

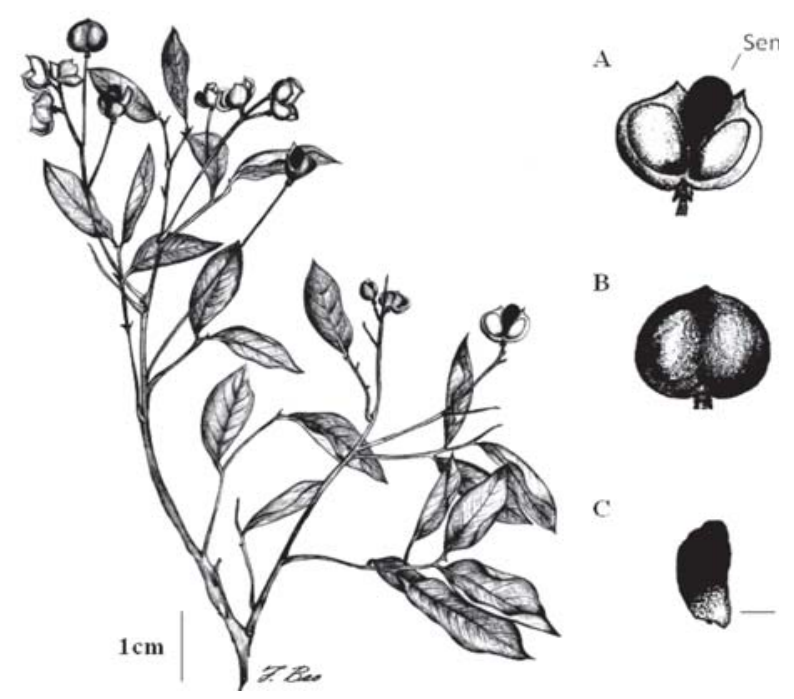

Figura 1 - Filotaxia do ramo de Matayba guianensis Aubl. exibindo em A - fruto aberto; $\mathrm{B}$ - fruto fechado; e C - semente com arilo carnoso.

Figure 1 - Phyllotaxy of the branch of Matayba guianensis Aubl. A - opened fruit, B - closed fruit; and C seed with fleshy aril.

Revista Árvore, Viçosa-MG, v.38, n.1, p.63-71, 2014 


\subsection{Efeito de substratos e recipientes sobre os parâmetros fitotécnicos}

O cultivo em qualquer dos substratos e recipientes não afetou o número de folhas das mudas. Entretanto, o comprimento das raízes foi maior em plantas cultivadas em tubete, com maiores comprimentos obtidos usando os substratos fibra de coco, terra e comercial (Tabela 2). Já nas bandejas de isopor o maior comprimento foi obtido utilizando substrato comercial, enquanto no recipiente saco de polietileno o substrato T-A-E proporcionou o menor desenvolvimento das raízes entre

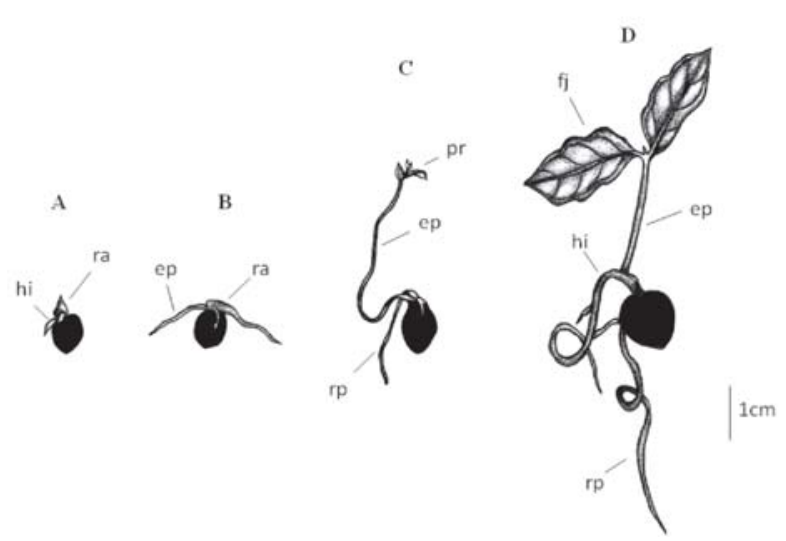

Figura 2 - Desenvolvimento inicial das plântulas de Matayba guianensis. A- início da germinação com a protrusão da radícula (ra), hipocótilo (hi); B- surgimento do epicótilo (ep); C- surgimento do protófilo (pr) e raiz primária (rp); e D- plântula completa, com raiz primária (rp), hipocótilo (hi), epicótilo (ep) e par de folhas jovens (fj).

Figure 2-Early development of seedlings Matayba guianensis. A- The early-germination radicle protrusion ( $\mathrm{ra}$ ), hypocotyl (hi) B-emergence of the epicotyl (ep); C-emergence of foliage leaf ( $p r)$ and primary root (rp); and D- seedling, complete with root primary (rp), hypocotyl (hi), epicotyls (ep) and pair of young leaves $(\mathrm{fj})$. todos os recipientes e substratos utilizados. No recipiente tubete, foram obtidos os melhores resultados para comprimento da raiz (Tabela 2).

A maior altura do caule também foi verificada em plantas cultivadas em tubete, em substrato comercial, areia ou fibra de coco. A menor altura entre todos os recipientes e o substrato foi verificada em plantas cultivadas no recipiente de isopor e em areia, não diferindo estatisticamente do substrato T-A-E e fibra de coco. No recipiente saco de polietileno, a altura das plantas cultivadas nos distintos substratos não apresentou diferenças significativas e foi semelhante aos maiores valores, verificados em plantas cultivadas no tubete.

Com relação à espessura do coleto, as maiores espessuras foram obtidas em plantas cultivadas no substrato terra ou fibra de coco, nos recipientes tubete e saco de polietileno. No recipiente de isopor, as maiores médias de espessura ocorreram em plantas cultivadas em substrato comercial.

\subsection{Análise de substratos e recipientes na massa seca}

A raiz, o caule e as folhas apresentaram maior massa seca em plantas cultivadas em tubete contendo substrato terra. Também em recipiente tubete e saco de polietileno e substratos terra ou fibra de coco, foram obtidas médias mais altas, em relação aos demais tratamentos. Já nas bandejas de isopor a maior massa seca de raiz, o caule e as folhas foram observadas em plantas cultivadas em substrato comercial e T-A-E.

Não houve diferença estatística entre as médias de massa seca de caule e folhas de plantas cultivadas em recipiente saco de polietileno.

\section{DISCUSSÃO}

O estudo sobre os caracteres morfológicos através das estruturas que constituem a planta é importante para auxiliar nas identificações botânicas (OLIVEIRA;

Tabela 1 - Porcentagem de emergência de plântulas de Matayba guianensis Aubl. nos recipientes em relação aos substratos. Table 1 - Percentage of seedling emergence of Matayba guianensis Aubl. the containers with respect to the substrates.

\begin{tabular}{lcccc}
\hline & & & $\%$ Emergência de plântulas \\
\hline Recipientes & Areia & T+A+E** & Comercial & Terra \\
Saco Polietileno & $20 \mathrm{aC}$ & $24 \mathrm{aC}$ & $43 \mathrm{bA}$ & Fibra de coco \\
Tubete & $25 \mathrm{aB}$ & $20 \mathrm{aB}$ & $32 \mathrm{cA}$ & $20 \mathrm{aC}$ \\
Isopor & $20 \mathrm{aB}$ & $26 \mathrm{aB}$ & $91 \mathrm{aA}$ & $20 \mathrm{aB}$ \\
\hline
\end{tabular}

* Médias com letras diferentes minúsculas na coluna e maiúsculas na linha diferem pelo teste de Tukey a $1 \%$ de probabilidade de erro. ** $(\mathrm{T}+\mathrm{A}+\mathrm{E})$ Terra+Areia+Esterco. 
Tabela 2 - Média geral do comprimento da raiz, altura do caule, espessura do coleto e número de folhas das plântulas de Matayba guianensis Aubl. em relação aos substratos em cada recipiente.

Table 2 - Overall average length of root, stem height, thickness of the girth and number of leaves of seedlings Matayba guianensis Aubl. in relation to the substrate in each container.

\begin{tabular}{|c|c|c|c|c|c|}
\hline Recipiente & Substrato & $\begin{array}{c}\mathrm{N}^{\circ} \text { folhas } \\
(\mathrm{CV} \%) 20,45\end{array}$ & $\begin{array}{c}\text { Comprimento } \\
\text { da raiz(cm) } \\
(\mathrm{CV} \%) 18,29\end{array}$ & $\begin{array}{c}\text { Altura do } \\
\text { caule }(\mathrm{cm}) \\
(\mathrm{CV} \%) 14,88\end{array}$ & $\begin{array}{c}\text { Espessura do } \\
\text { coleto(cm) } \\
(\mathrm{CV} \%) 13,44\end{array}$ \\
\hline Tubete & $\begin{array}{c}\text { Comercial } \\
\text { Terra } \\
\text { Areia } \\
\mathrm{T}+\mathrm{A}+\mathrm{E} \\
\text { Fibra de Coco }\end{array}$ & $\begin{array}{l}2,50 \text { a* } \\
2,35 \text { a } \\
2,20 \text { a } \\
2,40 \text { a } \\
2,45 \text { a }\end{array}$ & $\begin{array}{c}12,39 \mathrm{ab} \\
13,86 \mathrm{a} \\
11,04 \mathrm{~b} \\
8,70 \mathrm{c} \\
13,97 \mathrm{a}\end{array}$ & $\begin{array}{l}6,21 \mathrm{a} \\
5,43 \mathrm{~b} \\
6,25 \mathrm{a} \\
5,27 \mathrm{~b} \\
5,84 \mathrm{ab}\end{array}$ & $\begin{array}{l}0,91 \text { bc } \\
1,15 \text { a } \\
0,97 \text { b } \\
0,83 \text { c } \\
1,10 \text { a }\end{array}$ \\
\hline Recipiente & Substrato & $\begin{array}{c}\mathrm{N}^{\circ} \text { folhas } \\
(\mathrm{CV} \%) 28,15\end{array}$ & $\begin{array}{c}\text { Comprimento } \\
\text { da raiz(cm) } \\
(\mathrm{CV} \%) 38,27\end{array}$ & $\begin{array}{c}\text { Altura do } \\
\text { caule }(\mathrm{cm}) \\
(\mathrm{CV} \%) 15,28\end{array}$ & $\begin{array}{c}\text { Espessura do } \\
\text { coleto(cm) } \\
(\mathrm{CV} \%) 11,30\end{array}$ \\
\hline Isopor & $\begin{array}{c}\text { Comercial } \\
\text { Terra } \\
\text { Areia } \\
\mathrm{T}+\mathrm{A}+\mathrm{E} \\
\text { Fibra de Coco }\end{array}$ & $\begin{array}{l}2,35 \mathrm{a} \\
2,55 \mathrm{a} \\
2,45 \mathrm{a} \\
2,65 \mathrm{a} \\
2,60 \mathrm{a}\end{array}$ & $\begin{array}{c}10,16 \mathrm{a} \\
5,39 \mathrm{~b} \\
5,49 \mathrm{~b} \\
6,71 \mathrm{~b} \\
5,23 \mathrm{~b}\end{array}$ & $\begin{array}{l}5,76 \mathrm{a} \\
5,79 \mathrm{a} \\
4,67 \mathrm{~b} \\
5,31 \mathrm{ab} \\
5,24 \mathrm{ab}\end{array}$ & $\begin{array}{c}1,18 \mathrm{a} \\
0,84 \mathrm{c} \\
0,90 \mathrm{c} \\
1,12 \mathrm{ab} \\
1,07 \mathrm{~b}\end{array}$ \\
\hline Recipiente & Substrato & $\begin{array}{c}\mathrm{N}^{\circ} \text { folhas } \\
(\mathrm{CV} \%) 24,86\end{array}$ & $\begin{array}{l}\text { Comprimento } \\
\text { da raiz }(\mathrm{cm}) \\
(\mathrm{CV} \%) 21,68\end{array}$ & $\begin{array}{c}\text { Altura do } \\
\text { caule }(\mathrm{cm}) \\
(\mathrm{CV} \%) \text { 14,51 }\end{array}$ & $\begin{array}{c}\text { Espessura do } \\
\text { coleto }(\mathrm{cm}) \\
(\mathrm{CV} \%) 11,42\end{array}$ \\
\hline Saco Polietileno & $\begin{array}{c}\text { Comercial } \\
\text { Terra } \\
\text { Areia } \\
\mathrm{T}+\mathrm{A}+\mathrm{E} \\
\text { Fibra de Coco }\end{array}$ & $\begin{array}{l}2,20 \text { a } \\
2,40 \text { a } \\
2,55 \text { a } \\
2,55 \text { a } \\
2,70 \text { a }\end{array}$ & $\begin{array}{l}9,71 \mathrm{a} \\
9,67 \mathrm{a} \\
9,67 \mathrm{a} \\
3,94 \mathrm{~b} \\
8,85 \mathrm{a}\end{array}$ & $\begin{array}{l}5,63 \text { a } \\
6,11 \text { a } \\
6,15 \text { a } \\
6,09 \text { a } \\
6,20 \text { a }\end{array}$ & $\begin{array}{l}1,08 \mathrm{~b} \\
1,10 \mathrm{a} \\
0,99 \mathrm{c} \\
1,02 \mathrm{~b} \\
1,14 \mathrm{a}\end{array}$ \\
\hline
\end{tabular}

*Médias com letras diferentes na vertical diferem pelo teste de Tukey a 1\% de probabilidade de erro. ** (T+A+E) Terra+Areia+Esterco.

PEREIRA, 1987; SILVA; MATOS, 1991). A presença de folhas alternas e compostas, com folíolos inteiros (SOUZA; LORENZI, 2005; JUDD et al., 2009), é de ocorrência comum na família Sapindaceae.

O fruto do tipo cápsula origina-se no ovário súpero, e a junção se rompe na nervura mediana (BARROSO et al., 1999); é deiscente, pois se abre uma cápsula loculicida na parede do septo com a maturação, para expor as sementes (GONÇALVES; LORENZI, 2007), assemelhando-se às sapindáceas Dodonaea viscosa Jacq. e Pseudima frutescens (Aubl.) Radlk. (PAOLI; SARTI, 2008; PAOLI; BIANCONI, 2008). A semente preta e brilhante assemelha-se à de $P$. frutescens, por sua forma elíptica (LOMÔNACO; REIS, 2007). O processo germinativo do tipo hipógeo criptocotiledonar é caracterizado pelo fato de o limbo cotiledonar permanecer dentro da semente (GONÇALVES; LORENZI, 2007), que também é observado nas sapindáceas Sapindus saponaria L.; P. frutescens (PAOLI; SANTOS, 1998; PAOLI; BIANCONI, 2008) e Cupania vernalis Cambess. (VIEIRA et al., 2008).
A utilização de bandejas de isopor proporcionou alta emergência das mudas, provavelmente pela incidência de luz, que favoreceu as bandejas, pois os sacos plásticos dobravam conforme a irrigação, e os tubetes perdiam muito substrato; assim, as sementes afundavam. As bandejas também proporcionaram bom desenvolvimento da raiz, que pela forma de pirâmide invertida possibilita o crescimento reto das raízes para baixo (SCHORN; FORMENTO, 2003).

Com relação ao melhor substrato, a utilização da fibra de coco e substrato comercial proporcionou alta emergência. A fibra de coco promove aumento da porosidade, favorecendo o crescimento do sistema radicular, formando raízes finas e compridas e melhorando a fixação das mudas no campo (DIAS et al., 2009). Já a baixa emergência em areia também foi observada nas sapindáceas Magonia pubescens St. Hil. (COELHO et al., 2010) e Dodonea viscosa (L.) Jacq. (MEDEIROS; ABREU, 2005); isso pode ser explicado pela estrutura física da areia em promover rápida drenagem da água, diminuindo a embebição da semente (BUCCHESE et 
Tabela 3 - Efeito dos substratos em cada recipiente sobre a média de massa seca das raízes, caules e folhas das plântulas de Matayba guianensis Aubl.

Table 3 - Effect of substrate in each container, about the middle of the dry mass of roots, stems and leaves, seedlings Matayba guianensis Aubl.

\begin{tabular}{|c|c|c|c|c|}
\hline \multirow{2}{*}{ Recipiente } & \multicolumn{4}{|c|}{ Massa seca } \\
\hline & Substrato & Raiz (g)(CV \%) 47,06 & Caule (g)(CV\%) 62,75 & Folhas (g)(CV\%) 41,34 \\
\hline \multirow[t]{5}{*}{ Tubete } & Comercial & $0,008 \mathrm{c}^{*}$ & $0,013 \mathrm{~b}$ & $0,029 \mathrm{~b}$ \\
\hline & Terra & 0,021 a & 0,028 a & 0,043 a \\
\hline & Areia & 0,012 bc & $0,019 \mathrm{ab}$ & $0,042 \mathrm{ab}$ \\
\hline & $\mathrm{T}+\mathrm{A}+\mathrm{E}$ & 0,009 с & $0,016 \mathrm{~b}$ & $0,042 \mathrm{ab}$ \\
\hline & Fibra de coco & $0,015 \mathrm{~b}$ & $0,024 \mathrm{ab}$ & $0,037 \mathrm{ab}$ \\
\hline Recipiente & Substrato & Raiz (g)(CV\%) 31,32 & Caule (g)(CV\%) 55,74 & Folhas (g)(CV\%) 46,86 \\
\hline \multirow[t]{5}{*}{ Isopor } & Comercial & 0,019 а & 0,026 а & 0,039 а \\
\hline & Terra & $0,010 \mathrm{~b}$ & $0,014 \mathrm{~b}$ & 0,024 bc \\
\hline & Areia & $0,009 \mathrm{~b}$ & $0,015 \mathrm{~b}$ & 0,023 с \\
\hline & $\mathrm{T}+\mathrm{A}+\mathrm{E}$ & 0,018 a & 0,026 a & $0,037 \mathrm{ab}$ \\
\hline & Fibra de coco & $0,012 \mathrm{~b}$ & $0,019 \mathrm{ab}$ & 0,033 abc \\
\hline Recipiente & Substrato & Raiz (g)(CV\%) 45,79 & Caule (g)(CV\%) 60,43 & Folhas (g)(CV\%) 50,83 \\
\hline \multirow[t]{5}{*}{ Saco Polietileno } & Comercial & $0,008 \mathrm{~b}$ & $0,014 \mathrm{a}$ & 0,025 a \\
\hline & Terra & 0,016 a & 0,021 a & 0,031 a \\
\hline & Areia & $0,010 \mathrm{~b}$ & 0,013 a & 0,020 a \\
\hline & $\mathrm{T}+\mathrm{A}+\mathrm{E}$ & $0,012 \mathrm{ab}$ & 0,020 a & 0,028 a \\
\hline & Fibra de coco & $0,011 \mathrm{ab}$ & 0,018 a & 0,026 a \\
\hline
\end{tabular}

*Médias com letras diferentes na vertical diferem pelo teste de Tukey a 1\% de probabilidade de erro. ** $(\mathrm{T}+\mathrm{A}+\mathrm{E}) \mathrm{Terra}+\mathrm{Areia}+\mathrm{Esterco}$.

al., 2008). Já o substrato (T-A-E), pela presença de areia, se torna arenoso; logo, retém pouca água e nutrientes, diminuindo a emergência (GUREVITCH et al., 2009) e prejudicando o desenvolvimento das mudas. Já as mudas cultivadas em areia apresentaram as menores espessuras de coleto.

Com relação ao comprimento das raízes, as estrias internas do tubete permitem o alinhamento do sistema radicular, conferindo-lhe maior desenvolvimento (STURIUM et al., 2000). Contudo, Aguiar e Melo (1974) observaram bom desenvolvimento do sistema radicular em saco de polietileno. O mesmo foi descrito por Mesquita et al. (2009), em trabalho de germinação com Genipa americana L., similar ao trabalho de Cunha et al. (2008), que, comparando miniestaquia $\mathrm{x}$ tubete, constataram menor enraizamento e altura da raiz em tubete. Já para Schwengberg et al. (2002) o comprimento da raiz é diretamente proporcional ao tamanho do recipiente, os quais observaram maior comprimento em saco plástico, seguido de tubete e isopor.

Possivelmente, os melhores valores de comprimento da raiz encontrados em tubete ocorreram em razão de esse recipiente apresentar maior comprimento em relação às bandejas de isopor (SCHWENGBERG , 2002) e de o saco plástico limitar o crescimento das raízes, causando o "enrolamento" do sistema radicial no fundo do recipiente (VARGAS et al., 2011).

Macedo et al. (2011), em estudo com Tabebuia rosea-alba (Ridl.) Sandwith, notaram baixo valor do comprimento da parte aérea nos substratos terra, areia e esterco, apesar de suas características físicas proporcionarem maior porosidade e espaço preenchido por água, que pode possibilitar o aumento da parte aérea (PIO et al., 2005). Em conformidade, Mesquita et al. (2009) e Nicoloso et al. (2000), em estudos com espécies arbóreas, constataram maior espessura da base do coleto em recipiente de saco de polietileno.

Observou-se que os substratos influenciaram a emergência de plântulas de $M$. guianensis, conforme os resultados encontrados, assim como no crescimento e vigor das mudas, mas de maneira diferente, ou seja, os substratos que proporcionaram maior porcentagem de emergência não foram os mesmos que levaram à produção de mudas de melhor qualidade. A diferença 
com relação à emergência de plântulas pode ser explicada, provavelmente, pela capacidade de retenção de água de cada substrato e pelas características intrínsecas que regulam o fluxo de água para as sementes (ANDRADE; PEREIRA, 1994).

A maior massa seca encontrada em terra e T-AE também foi evidenciada por Duarte e Nunes (2012), em trabalho com produção de mudas de Bauhinia foficata Link, que obtiveram maiores valores em substrato areia+terra. Já Schwengberg et al. (2002), em trabalho com os mesmos recipientes, mas na propagação de ameixeiras, não observaram diferenças significativas na massa seca.

As sementes apresentaram diferentes necessidades de substratos e recipientes. Assim, pode-se observar que há necessidade de mais estudos com sementes florestais para produção de mudas, pois cada espécie apresenta comportamento muito diferente, a fim de promover a regeneração de áreas e auxiliar na identificação das espécies.

\section{CONCLUSÃO}

Para Matayba guianensis, sugere-se que a produção de mudas seja feita em sementeiras apropriadas para a emergência no substrato comercial e na fibra de coco, seguida de transplante das plântulas para os recipientes saco plástico ou tubete, contendo substrato comercial como o mais adequado para o crescimento vigoroso das mudas.

\section{REFERÊNCIAS}

AGUIAR, I. B.; MELLO, H. A. Influência do Recipiente na produção de mudas e no envolvimento inicial após o plantio no campo, de Eucalyptus grandis Hill ex Maiden e Eucalyptus saligna Smith. IPEF, n.8, 1974.

\section{ALLEM, A. C.; VALLS, J. F. M. Recursos} forrageiros nativos do Pantanal Matogrossense. Brasília: Embrapa-Cenargen, 1987. (Documentos, 8)

ANDRADE, A. C. S.; PEREIRA, T. S. Efeito do substrato e da temperatura na germinação e no vigor de sementes de Cedro - Cedrela odorata L. (MELIACEAE). Revista Brasileira de Sementes, v.16, n.1, p.34-40, 1994.
APG III. An update of the Angiosperm Phylogeny Group classification for the orders and families of flowering plants: APG III. Botanical Journal of the Linnean Society, v.161, p.105-121, 2009.

BARROSO, G. M. et al. Frutos e sementes: morfologia aplicada à sistemática de dicotiledôneas. Viçosa, MG: Universidade Federal de Viçosa, 1999. 443p.

BRASIL. Ministério da Agricultura e Reforma Agrária. Regras para análise de sementes. Brasília: SNDA/DNDV/CLAV, 2009.

BUCCHESE, R. A. et al. Efeito de diferentes tipos de solos na germinação de sementes de Tabebuia heptaphylla em casa telada. Cerne, v.14, n.1, p.62-67, 2008.

CARneiro, J. G. A. Produção e controle de qualidade de mudas florestais. Curitiba: UFPR/FUPEF, Campos: UENF, 1995. 451p.

CARVAlHO, A. M. C.; OLIVEIRA, P. E. A. M. Estrutura da guilda de abelhas visitantes de Matayba guianensis Aubl. (Sapindaceae) em vegetação do Cerrado. Oecologia Australis, v.14, n.1, p.40-66, 2010.

COELHO, M. F. B. et al. Substratos para a emergência de plântulas de Magonia pubescens St. Hil. Revista Brasileira Ciências Agrárias, v.5, n.1, p.80-84, 2010.

CUNHA, A. C. M. C. M.; WENDLING, I.; SOUZA JÚNIOR, L. Miniestaquia em sistema de hidroponia e em tubetes de corticeira-do-mato. Ciencia Florestal, v.18, n.1, p.85-92, 2008.

CUNHA, A. O. et al. Efeitos de substratos e das dimensões dos recipientes na qualidade das mudas de Tabebuia impetiginosa (Mart. Ex D.C.) Standl. Revista Árvore, v.29, n.4, p.507-516, 2005.

DIAS, T. J. et al. Desenvolvimento e qualidade nutricional de mudas de mangabeiras cultivadas em substratos contendo fibra de coco e adubação fosfatada. Revista Brasileira de Fruticultura, v.31, n.2, p.512-523, 2009.

Revista Árvore, Viçosa-MG, v.38, n.1, p.63-71, 2014 
DUARTE, D. M.; NUNES, U. R. Crescimento inicial de mudas de Bauhinia forficata Link em diferentes substratos. Cerne, v.18, n.2, p.327334, 2012.

FERREIRA, R. A. et al. Caracterização morfológica de fruto, semente, plântula e muda de Dipteryx alata Vogel - Baru (Leguminosae Papilionoideae). Cerne, v.4, n.1, p.73-87, 1998.

FERRUCCI, M. S. Flora del Paraguay (Sapindaceae). In: SPICHIER RAVEN, P. H. (Ed.). Conservatoire et Jardin botaniques de la Ville de Genéve (Genéva). St. Louis: Missouri Botanical Garden, 1991. 18-144,.

FONT-QUER, P. Dicionário de Botânica. Barcelona: Labor. 1963.

GOMES, J. M.; COUTO, L.; BORGES, R. Efeitos de diferentes substratos na produção de mudas de Eucalyptus grandis W. Hill ex Maiden, em "winstrip”. Revista Árvore, v.15, n.1, p.35-42, 1991.

GONÇALVES, E. G.; LORENZI, H. Morfologia vegetal: organografia e dicionário ilustrado de morfologia das plantas vasculares. São Paulo: Instituto Plantarum de Estudos da Flora, 2007.

GUREVITCH, J.; SCHEINER, S. M.; FOX, G. A. Ecologia vegetal. 2.ed.. Porto Alegre: Artmed, 2009.

JOLY, A. B. Botânica: introdução à taxonomia vegetal. São Paulo: Nacional, 1993.

JUDD, W. S. et al. Sistemática vegetal: um enfoque filogenético. 3.ed. Porto Alegre: Artmed, 2009.

LOMÔNACO, C.; REIS, N. S. Produção de frutos e sementes em Miconia fallax DC.

(Melastomataceae) e Matayba guianensis Aubl. (Sapindaceae) em duas áreas de Cerrado no Triângulo Mineiro. Revista Biologia Neotropical, v.4, n.1, p.13-20, 2007.

MACEDO, M. C. et al. Produção de mudas de Ipêbranco em diferentes substratos. Cerne, v. 17, n.1, p. 95-102, 2011.

MEDEIROS, A. C. S.; ABREU, D. C. A. Instruções para testes de germinação de sementes florestais nativas da Mata Atlântica. Colombo: Embrapa, 2005. (Comunicado Técnico)

Revista Árvore, Viçosa-MG, v.38, n.1, p.63-71, 2014
MESQUITA, J. B. et al. Avaliação da composição de substratos e recipientes na produção de mudas de jenipapo (Genipa americana L.). Acta Forestalis, v.1, n.1, p.37-45, 2009.

NICOLOSO, F. T. et al. Recipientes e substratos na produção de mudas de Maytenus ilicifolia E Apuleia leiocarpa. Ciência Rural, v.30, n.6, p.987-992, 2000.

OLIVEIRA, E. C. \& PEREIRA, T. S. Euphorbiaceae - Morfologia da germinação de algumas espécies. Revista Brasileira de

Sementes, v.9, n.1, p.9-29, 1987.

PACHECO, M. V. et al. Efeito de temperaturas e substratos na germinação de sementes de Myracrodruon urundeuva Fr. All.

(ANACARDIACEAE). Revista Árvore, v.30, n.3, p.359-367, 2006.

PAOLI, A. A. S.; SANTOS, M. R. O.

Caracterização morfológica de frutos, sementes e plântulas de Sapindus saponaria L.

(SAPINDACEAE). Revista Brasileira de

Sementes, v.20, n.2, p.147-153, 1998.

PAOLI, A. A. S.; BIANCONI, A. Caracterização morfológica de frutos, sementes e plântulas de Pseudima frutescens (Aubl.) Radlk. (SAPINDACEAE). Revista Brasileira de Sementes, v.30, n.2, p.146-155, 2008.

PAOLI, A. A. S.; SARTI, J. Morfoanatomia e desenvolvimento de frutos e sementes de Dodonaea viscosa. Revista Brasileira de Sementes, v.30, n.2, p.33-42, 2008.

PIO, R. et al. Substratos na produção de mudas de Jabuticaba. Revista Brasileira de Agrociência, v.11, n.4, p.425-427, 2005.

POPINIGS, F. Fisiologia da semente. Brasilia: Agiplan, 1985.

RESSEL, K. et al. Ecologia morfofuncional de plântulas de espécies arbóreas da Estação Ecológica do Panga, Uberlândia, Minas Gerais.

Revista Brasileira de Botânica, v.27, n.2, p.311-323, 2004. 
SANTOS, J. G. et al. Germinação e crescimento de mudas de Biribazeiro (Rollinia mucosa (Jack) Baill) no Brasil. IDESIA, v.27, n.2, p.55-59, 2009.

SCHWENGBERG, J. E. et al. Utilização de diferentes recipientes na propagação de ameixeira através de estacas. Revista Brasileira Fruticultura, v.24, n.1, p.285-288, 2002.

\section{SCHORN, L. A.; FORMENTO, S. Silvicultura}

I: Produção de mudas florestas. Blumenau: Universidade Regional de Blumenau, Centro de Ciências Tecnológicas, Departamento de Engenharia Florestal, 2003.

SILVA, F. A. S.; AZEVEDO, C. A. V. Principal components analysis in the software AssistatStatistical Attendance. In: WORLD CONGRESS ON COMPUTERS IN ACRIGULTURE, 7., Reno-NVUSA. Proceedings... Reno-NV-USA: American Society of Agricultural and Biological Engineers, 2009.

SILVA, K. B. et al. Caracterização morfológica de frutos, sementes e germinação de Sideroxylon obtusifolium (Roem. e Schult.) Penn. (Sapotaceae). Revista Árvore, v.36, n.1, p.59-64, 2012.

SILVA, L. M. M.; MATOS, V. P. Morfologia de semente e da germinação de Eryhrina velutina Willd. Revista Árvore, v.15, n.2, p.137-143, 1991.
SOMNER, G. V.; FERRUCCI, M. S.; ACEVEDORODRÍGUES, P. Sapindaceae. In: FORZZA, R. C. et al. Lista de Espécies da Flora do Brasil. Rio de Janeiro: Jardim Botânico do Rio de Janeiro. 2010.

SOUZA, V. C.; LORENZI, H. Botânica sistemática: guia ilustrado para identificação das famílias de Angiospermas da flora brasileira, baseado em APG II. Nova Odessa: Instituto Plantarum, 2005.

STURIUM, J. A.; GRAÇA, L. R.; ANTUNES, J. B. $M$. Produção de mudas de espécies de rápido crescimento por pequenos produtores. Colombo: Embrapa Florestas, 2000. (Circular Técnica, 37)

VARGAS, F. S. et al. Efeitos da mudança de recipiente em viveiro na qualidade de mudas de Cassia leptophylla Vogel, Eugenia involucrata DC. e de Cedrela fissilis Vell. Revista Acadêmica: Ciências Agrárias e Ambientais, v.9, n.2, p.169-177, 2011.

VIEIRA, C. V. et al. Germinação e armazenamento de sementes de Camboatã (Cupania vernalis Cambess.) SAPINDACEAE. Ciência Agrotecnologia, v.32, n.2, p.444-449, 2008.

VIDAL, V. N.; VIDAL, M. R. R. Botânica: organografia. Viçosa, MG: Universidade Federal de Viçosa, 1995. 
